\title{
Advanced Worker Protection System
}

\section{INNOVATIVE TECHNOLOGY SUMMARY REPORT}

\author{
demonstrated at
}

Oceaneering Space Systems, Houston, Texas, and Kansas State University, Manhattan, Kansas

\section{prepared for}

\section{U.S. Department of Energy}

Office of Environmental Management

Office of Science and Technology

April 1996 


\section{DISCLAIMER}

This report was prepared as an account of work sponsored by an agency of the United States Government. Neither the United States Government nor any agency thereof, nor any of their employees, makes any warranty, express or implied, or assumes any legal liability or responsibility for the accuracy, completeness, or usefulness of any information, apparatus, product, or process disclosed, or represents that its use would not infringe privately owned rights. Reference herein to any specific commercial product, process, or service by trade name, trademark, manufacturer, or otherwise does not necessarily constitute or imply its endorsement, recommendations, or favoring by the United States Government or any agency thereof. The views and opinions of authors expressed herein do not necessarily state or reflect those of the United States Government or any agency thereof.

This report has been reproduced directly from the best available copy.

Available to DOE and DOE Contractors from the Office of Scientific and Technical Information, P.O. Box 62, Oak Ridge, TN 37831; prices available from (615) 576-8401.

Available to the public from: The Center for Environmental Management Information, P.O. Box 23769, Washington, DC 20026-3769 (1-800) 736-3282 .

or

The U.S. Department of Commerce, Technology Administration, National Technical Information Services, Springfield, VA 22161 (703) 487-4650. 


\section{Advanced Worker Protection System}

\section{INNOVATIVE TECHNOLOGY SUMMARY REPORT}

demonstrated at

Oceaneering Space Systems, Houston, Texas, and Kansas State University, Manhattan, Kansas

prepared for

U.S. Department of Energy

Office of Environmental Management

Office of Science and Technology

April 1996 


\section{DISCLAIMER}

Portions of this document may be illegible in electronic image products. Images are produced from the best available original document. 


\section{TABLE OF CONTENTS}

1 SUMMARY

page 1

2 TECHNOLOGY DESCRIPTION

page 3

3 PERFORMANCE

page 6

4

TECHNOLOGY APPLICABILITY \& ALTERNATIVES

page 8

$5 \quad \cos T$

page 9

6 REGULATORYIPOLICY ISSUES

page 10

7 LESSONS LEARNED

page 11

APPENDICES

A References 


\section{SECTION I}

\section{SUMMARY}

\section{Technology Description}

The Advanced Worker Protection System (AWPS) is a liquid-air-based, self-contained breathing and cooling system with a duration of $2 \mathrm{hrs}$. AWPS employs a patented system developed by Oceaneering Space Systems (OSS), which was supported by the Department of Energy's (DOE's) Morgantown Energy Technology Center through a cost sharing research and development contract. The heart of the system is the life-support backpack that uses liquid air to provide cooling as well as breathing gas to the worker. The backpack is combined with advanced protective garments, an advanced liquid cooling garment (LCG), a respirator, and communications and support equipment.

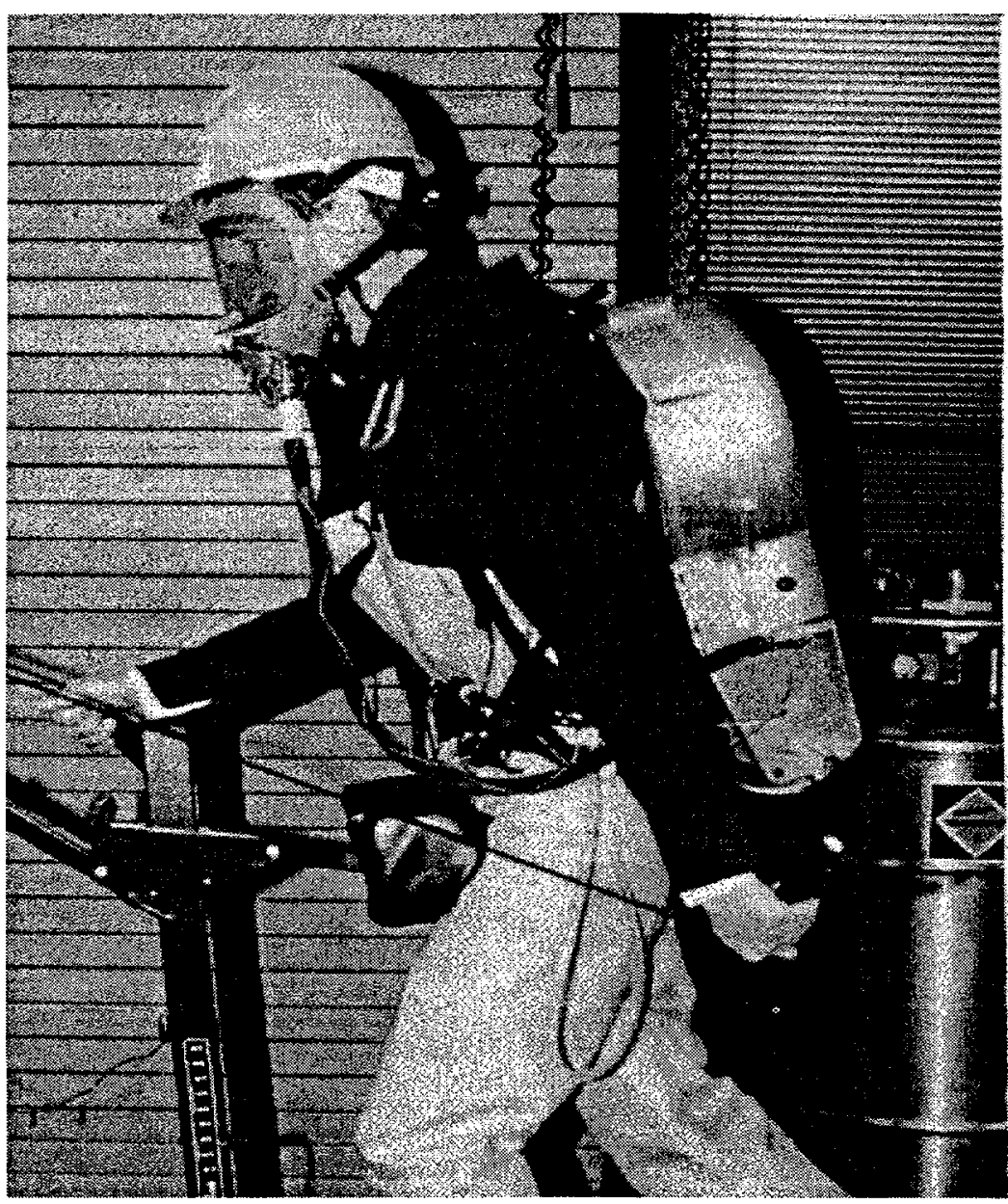

Figure 1. Worker wearing the Advanced Worker Protection System. 


\section{Technology Status}

Development of AWPS will involve two phases: Phase I, which encompassed the development and testing of the AWPS prototype, and Phase II, which will culminate in a full-scale, certified, preproduction AWPS demonstration at a DOE site. OSS has completed Phase I and issued the "Phase I Topical Report, Advanced Worker Protection System," dated June 15, 1995 (Appendix A).

Phase I included the development of a full-scale, prototype advanced worker protection ensembleeverything the worker will wear, with subscale support equipment-suitable for integrated testing and preliminary evaluation.

- In-house testing focused on component testing; subsystem testing; system testing; and limited, complete ensemble testing.

- Kansas State University Institute for Environmental Research (KSU IER) testing focused on human subject evaluation of AWPS in the areas of endurance and comfort and compared the results with a self-contained breathing apparatus (SCBA).

Phase I testing demonstrated (1) the ability of AWPS to meet the performance criteria of the Portable LifeSupport System (PLSS) without any major failure and (2) the efficacy of the liquid cooling approach when integrated with chemical protective clothing. These test results will guide development of the Phase II AWPS.

\section{Key Results}

The prototype unit development and testing under Phase I has demonstrated that AWPS has the ability to meet performance criteria. These criteria were developed with an understanding of both the AWPS capabilities and the DOE decontamination and decommissioning (D\&D) activities protection needs.

The efficiency of each worker is expected to increase by more than $100 \%$. Implementing this system will

- decrease the size of the secondary waste stream,

- decrease the number of workers required for a given task,

- decrease the amount of time it takes for each job, and

- create a safer working environment.

\section{Contacts}

Technical

Bruce Caldwell/Jeff Myers, Oceaneering Space Systems, (713) 488-9080

\section{Management}

Steve Bossart, U.S. Department of Energy, Morgantown Energy Technology Center, (304) 285-4643

\section{Licensing Information}

Bruce Caldwell, Oceaneering Space Systems, (713) 488-9080 


\section{TECHNOLOGY DESCRIPTION}

\section{System Configuration and Operation}

AWPS is a low pressure ( $40 \mathrm{psi}$ ), liquid-air-based, self-contained breathing and cooling system having a National Institute of Occupational Safety and Health (NIOSH) 2-hr. duration rating. It consists of the primary life-support components mounted in a backpack. The backpack is combined with the following:

- a respirator,

- a full-body LCG,

- outer garment options of either a splash suit or a totally encapsulated vapor-protection suit, and

- communications equipment.

A durable/resuable material, Chemfab "Challenge 6400," met the requirements for the Level A vaporprotection suit. A disposable material was selected for the Level B liquid-splash-protection suit fabricated by Mar-Mac Manufacturing. Mar-Mac Manufacturing was chosen because of its access to and experience with the material, which is available from E. I. DuPont de Nemours \& Co., Inc., as well as its specialized protective clothing heat-sealing capabilities. All components are commercially available.

The heart of the system is PLSS (see Figure 2), which could also be used with many currently available protective garments.

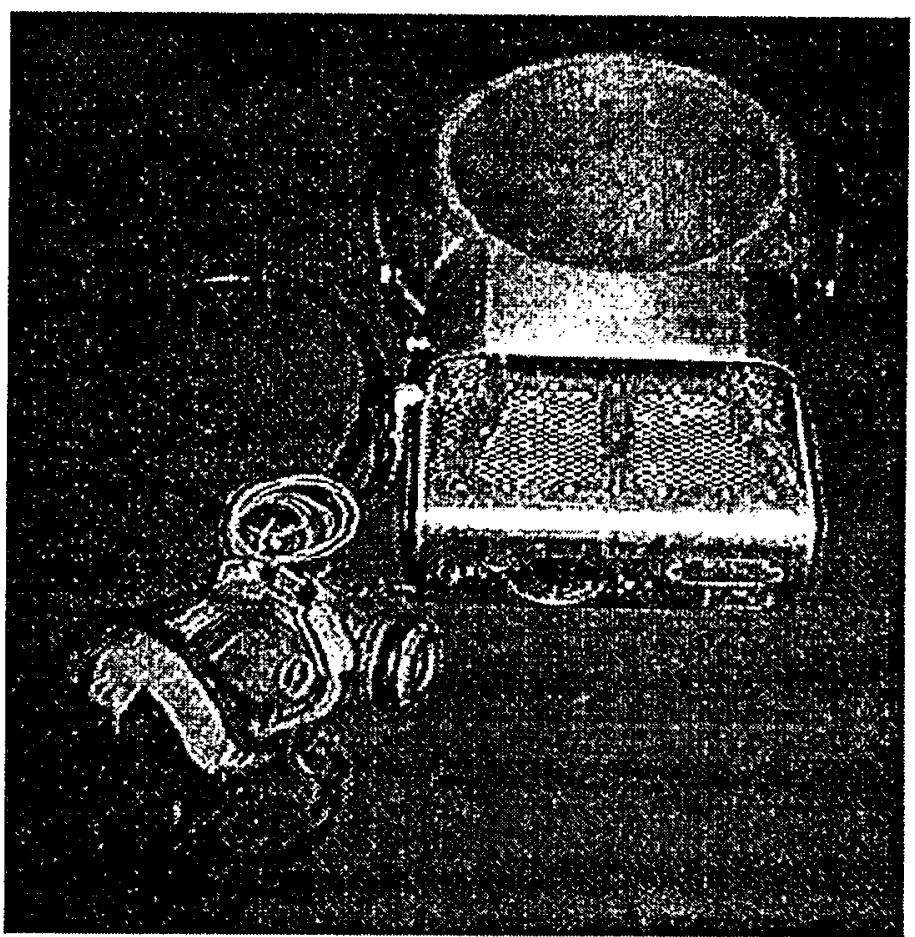

Figure 2. The Portable Life-Support System (PLSS). 
The backpack includes the vacuum-jacketed vessel or dewar, which contains the cryogenic liquid air (see Figure 3).

- The liquid air is vaporized and warmed in a heat exchanger, cooling the water supplied to LCG.

- The warmed air is regulated to the appropriate pressure and delivered to the face mask and regulator.

- The cooled water circulates through the tubes and patches of the full-body LCG, removing heat from the user, with the warmed water returned to the heat exchanger.

The cooling supplied to the user varies automatically with the user's breathing rate and can be controlled manually by increasing the cryogen flow through the heat exchanger.

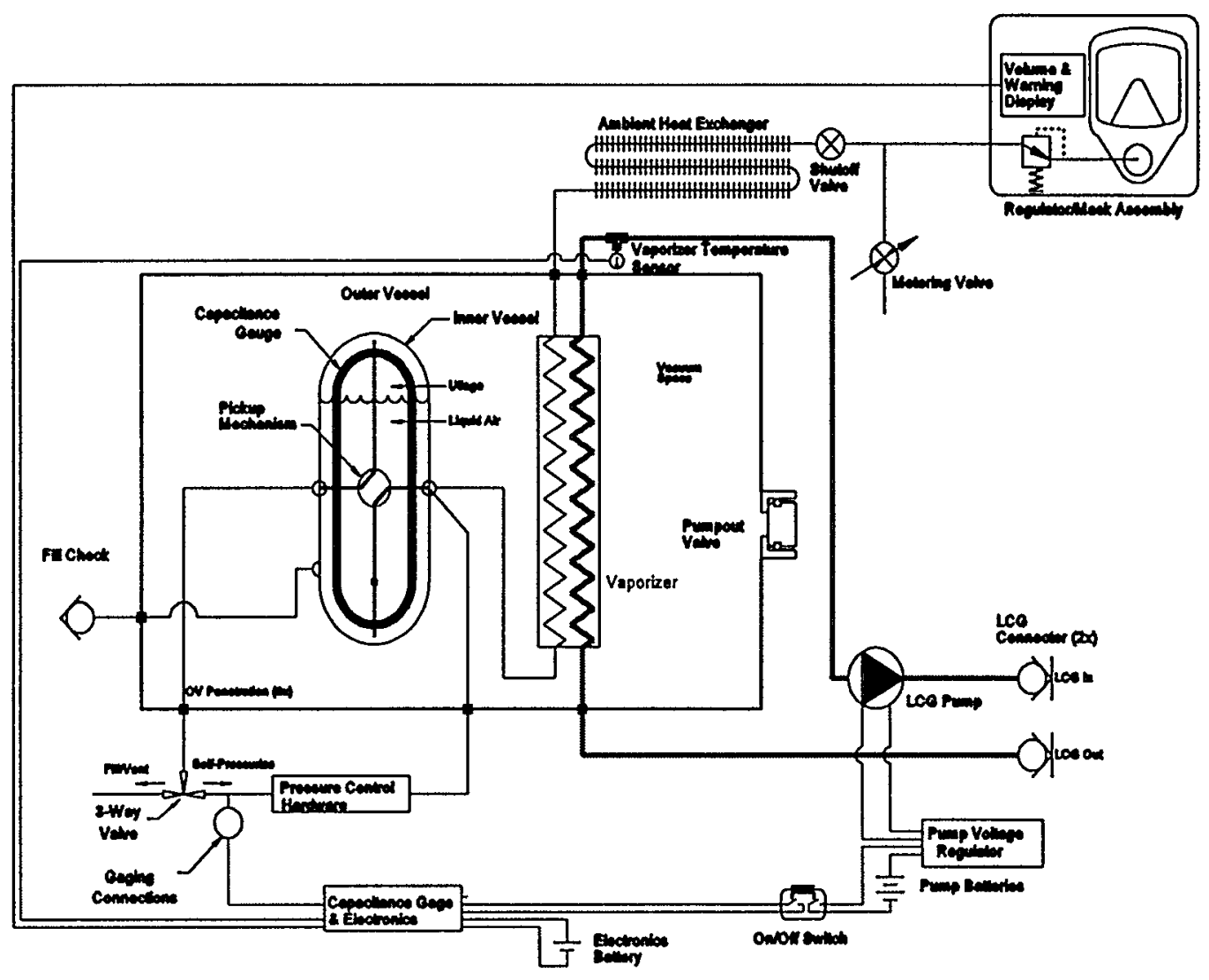

Figure 3. Hazardous materials Portable Life-Support System functional schematic. 
A recharge station is required to fill the dewar on AWPS with liquid air (see Figure 4). The system uses liquid nitrogen to convert compressed breathing air into subcritical liquid air and can be added to most existing SCBA recharging systems.

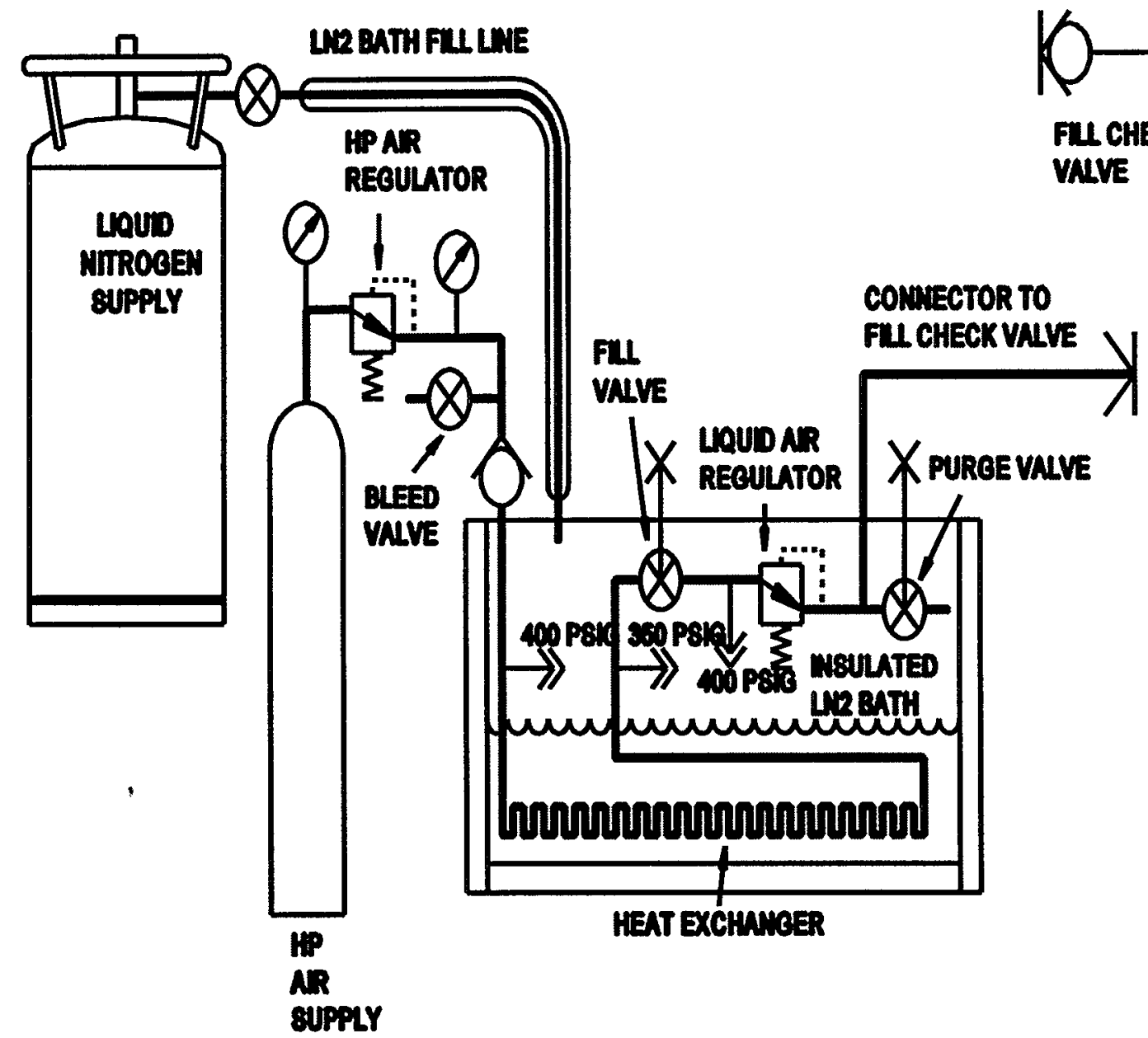

Figure 4. Schematic of recharge system. 


\section{SECTION 3}

\section{PERFORMANCE}

\section{Operational Performance (Phase I)}

- The AWPS prototype meets the established performance criteria:

- the backpack will be NIOSH certified as a 2-hr., positive pressure SCBA,

- the backpack operates in any orientation,

- LCG provides effective cooling at work rates up to 500 watts, and

- AWPS will extend working times by at least $100 \%$ in comparison to existing protective garments/SCBA ensembles.

- The Phase I prototype hardware verified the design approaches for AWPS. AWPS can reduce DOE inventory needs, reduce protection equipment selection problems, enhance personnel protection and safety, and provide significant gains in worker productivity.

- Independent testing at KSU IER provided a comprehensive human subject evaluation of AWPS showing significant increases in human subject endurance and comfort when compared to traditional SCBA ensembles. The test subjects were able to work for twice as long using the prototype AWPS compared to the standard SCBA. This testing provided the performance data needed to optimize the Phase II hardware design as well as independent verification of AWPS's effectiveness.

- Core temperature is an excellent measure of actual thermal condition and shows how much heat the body is losing or storing. Figure 5, a graph of core temperature for one subject in Level B (splash suit) protective gear, exercising at a constant rate, shows the dramatic effect the AWPS cooling can have. Note that the core temperature actually dropped while using AWPS.

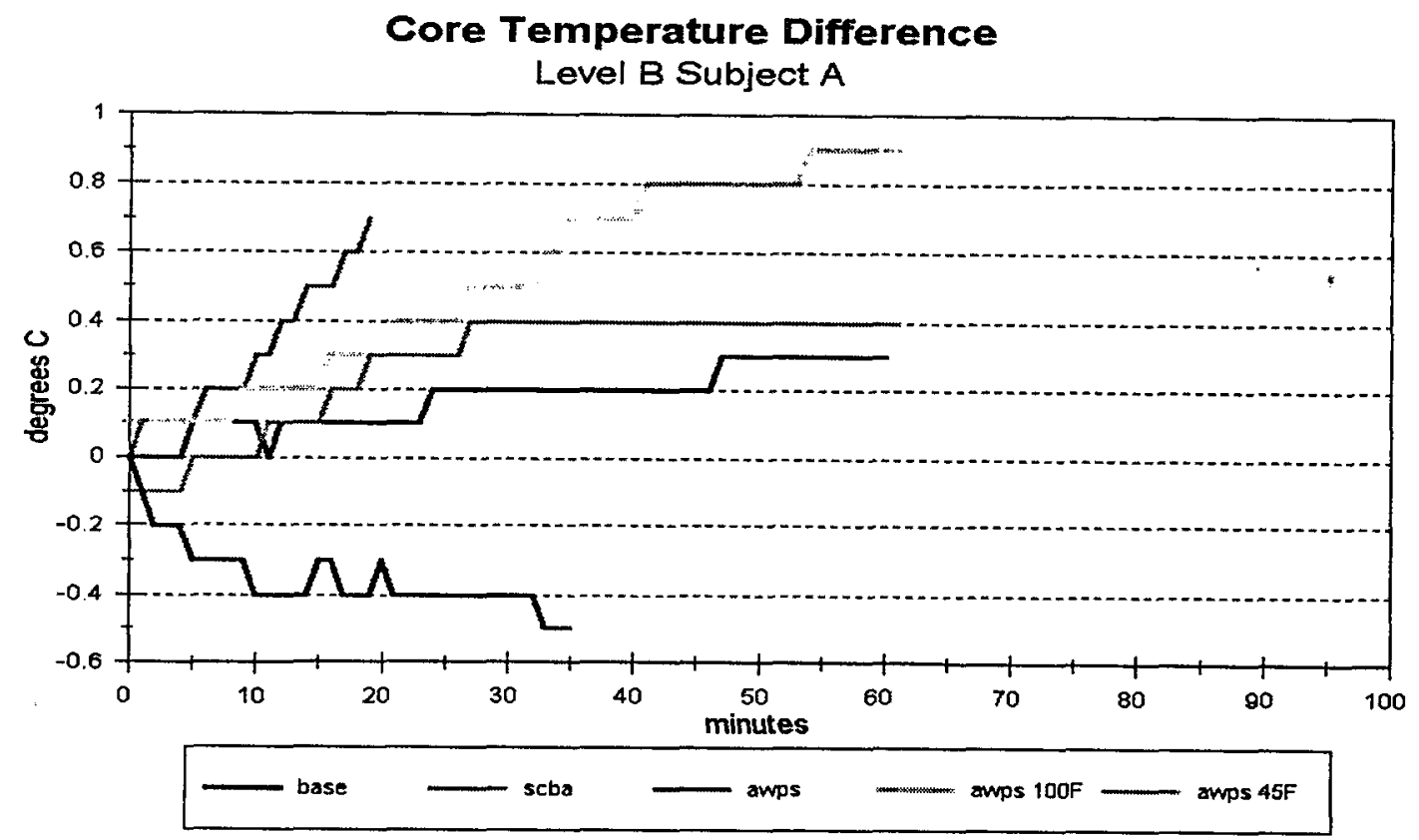

Figure 5. Core body temperature difference during Kansas State testing. 


\section{Demonstration Plan (Phase II)}

Phase II activities have been initiated and will include the following.

- Design modification and optimization.

- Incorporation of sizing requirements into the suit design.

- Evaluation of the preliminary Phase II design:

-part of the International Union of Operating Engineers National Hazmat Program

-two sessions scheduled for June and July 1996.

- Full-scale AWPS development.

- Certification and outside evaluation of system/components:

-NIOSH certification as positive pressure demand SCBA

-DOE Los Alamos evaluation of protective garments.

- Production version AWPS Development Topical Report.

- DOE site demonstration of preproduction NIOSH-certified AWPS at a training facility at a DOE site (scheduled for early 1997). 


\section{TECHNOLOGY APPLICABILITY AND} ALTERNATIVE TECHNOLOGIES

\section{Technology Applicability}

One of DOE's top priorities is to ensure that its workers are adequately protected during remediation activities.

DOE D\&D workers face a multitude of hazards at each site, including

- contamination (radiological or chemical);

- $\quad$ physical (punctures, cuts, tears, and abrasions);

- thermal (contact with molten metal, flame impingement, chemical flash fires); and

- thermal stress (heat- or cold-related exposures).

The work involved in D\&D of many DOE facilities throughout the DOE complex requires that hands-on tasks be completed by workers in protective suits and respirators.

AWPS establishes a revolutionary and distinctive category of personal protective equipment (PPE) providing respiratory protection, full-body skin protection, and full-body cooling, all in one package.

\section{Competing Technologies}

Current respiratory protection systems offer limited-duration protection and little or no relief from heat stress for extended work periods or in hot environments. Cool-down periods are often required after $45 \mathrm{~min}$ of work. When cooling is provided, it is a separate system, it is bulky, and it adds significant weight to the overall worker protection ensemble.

\section{Technology Maturity}

Phase I demonstrated that AWPS has the ability to meet performance criteria. These criteria were developed with an understanding of the AWPS capabilities combined with identification of protection needs for DOE D\&D activities.

Development and testing of the prototype system in Phase I has led to design changes that are being incorporated into Phase II and that will lead to a full-scale, certified, preproduction AWPS demonstrated at a DOE site. 


\section{SECTION 5}

\section{Cost}

\section{Introduction}

The life-cycle cost (LCC) and benefit analysis was based on the Phase I design and test data.

LCC of personal protective clothing and equipment used in the existing ensembles was determined based on data obtained from three DOE remediation sites. The data were gathered using an elaborate survey and interview process.

\section{Assumptions}

The AWPS LCC is the sum of the labor and material costs associated with the purchase; operations; cleaning and decontamination; maintenance; and repair, storage, and disposal of the protective clothing and equipment.

The degree of work activity was based on a 5000-work-hour scenario (250 hrs. for Level A activities and 4750 hrs. for Level B activities).

For the base case, the current Level A ensemble consists of a limited use (one time), totally encapsulated suit constructed of a lightweight plastic, laminate-based, material; attached gloves; and a reusable (1000 times), 30 - or 60-min SCBA.

The AWPS Level A ensemble also includes a reusable (five times), totally encapsulating suit constructed of a durable material, attached gloves, an inner cooling garment, and the reusable (1000 times) liquid air PLSS.

The Level B scenario includes the same ensembles but a liquid splash-protective suit is substituted for the totally encapsulating suit. Both are limited use (one time).

\section{Costs Analysis}

For the base case, the overall LCC (labor and material) for the existing ensemble was $\$ 1,676,851$. For AWPS, an LCC of $\$ 980,886$ was achieved, representing a savings of $\$ 695,965,41 \%$, over the existing base case ensemble. (Note that the more than twofold increase in worker productivity is factored into this.) The sensitivity analysis performed on the key variables showed continued cost benefits even under the least favorable circumstances. 


\section{REGULATORYIPOLICY ISSUES}

\section{Regulatory Considerations}

All PPE must meet specific federal regulatory requirements. There are individual requirements for the respirator, container, protective suits, helmet, and support equipment. Use of PPE is controlled by these regulations, and the suit and respirator must complete certification testing as part of additional regulatory requirements.

- AWPS protective clothing design followed the existing National Fire Protection Association standards for hazardous chemical emergencies and operations, equivalent to Level A and B protective suits, and met the acceptance protocols established by DOE, as appropriate.

- The regulation with the most impact on the development of the respiratory portion of AWPS is 30 CFR Part 11. This regulation is for certification of respiratory protective devices. NIOSH is the primary controlling organization for this regulation. AWPS will be certified to Title 30 , which is essential for use in hazardous environments.

- The regulation that controls the general use of respirators is 29 CFR Part 1910.134, which is controlled by the Occupational Safety and Health Administration (OSHA). OSHA also controls safety and health for hazardous materials handling with 29 CFR 1910.120, the Hazardous Waste Operations and Emergency Response Standard.

\section{Safety, Risks, Benefits, and Community Reaction}

\section{Worker Safety}

- The independent testing at KSU IER demonstrated significant increases in human subject endurance and comfort when compared to traditional SCBA ensembles. AWPS can enhance personnel protection and safety while providing significant gains in worker productivity.

\section{Environmental Impacts}

- The AWPS Level A ensemble is a reusable, totally encapsulating suit, constructed of a durable material, and attached gloves. This reduces the secondary waste and disposal costs associated with clothing and equipment. 


\section{LESSONS LEARNED}

\section{Design Issues}

Phase I testing at OSS and KSU did not uncover any major design deficiencies that cannot be factored into the Phase II hardware design. The following changes are a result of the Phase I testing.

- Backpack controls will be much more integrated for worker ease of operation.

- To reduce fogging of the visor, solutions such as venting exhaled gasses out the side of the suit, routing some air from PLSS to flush across the visor, and the application of an antifogging agent will be considered.

- High wear/stress areas on the protective clothing and LCG were identified and will be strengthened.

- Minor changes will be made to the suits, including a wider range of sizes, for ease in donning.

- Modification to the metering valve to limit gas flow and adjustments to the LCG water lowtemperature warning light will also be made.

\section{Technology Limitations/Needs for Future Development}

At present there are no technology limitations. The hardware design changes discussed above are being incorporated into the latest prototype system. 


\section{APPENDIX A}

\section{REFERENCES}

Horne, T. 1996. Cost Benefit Analysis, Worker Protection System, Hazardous Waste Remedial Actions Program, Oak Ridge, Tenn.

Todd, R. 1995. Phase I Performance/Design Criteria Review Topical Report, Advanced Worker Protection System, Oceaneering Space Systems, March.

Todd, R. 1995. Phase I Final Topical Report, Advanced Worker Protection System, Oceaneering Space Systems, June.

Oceaneering Space Systems Advanced Worker Protection System Fact Sheet. 